\title{
STUDY ON THE WESTLEY MACLEAN MODEL AND THE CO-ORIENTATION MODEL AND THEIR EXEMPLIFICATION IN AN INDUSTRIAL ENTERPRISE
}

\author{
Mihaela BUCUR ${ }^{1}$, Andreea BAN ${ }^{2}$ \\ ${ }^{1,2}$ George Emil Palade University of Medicine, Pharmacy, Science, and Technology of Târgu Mureș \\ 38 Gheorghe Marinescu st., no. 38, 540139, Targu Mures, Romania \\ 1mihaela.bucur@umfst.ro \\ ${ }^{2}$ andreea.ban@umfst.ro
}

\begin{abstract}
The present paper makes an incursion into the new and complex models of communication that can be found in literature, trying to identify their graphic decoding and their applicability in an industrial enterprise. The authors identified real examples for each model under investigation, so the purpose of the paper is to emphasize the importance of communication and the applicability of the new methods of communication in engineering.
\end{abstract}

Key words: communication, communication models, communications in industrial enterprise, Westley MacLean Model, Co-Orientation model

\section{The context of the research}

Each form of communication has its own specificity and creates its own models. There are also models that cross the barriers of a certain form and which can be adapted to any situation, for any type of communication.

For example, Harold Dwight Lasswell describes a communication model that consists of five basic elements: Who - says what -by what channel - for whom - to what effect. The communication model of Shannon and Weaver (information source, message, transmitter, signal, channel and receiver) includes an interesting concept of noise or interference that distorts the understanding between the speaker and the listener. The Westley and McLean model introduces the role of the channel that can modify the original message.

Some researchers think that the concept of the message should be completely eliminated, because it involves a self-contained unit, which is essentially disconnected from the interpersonal communication. The notion of code introduced by Jakobson and Saussure has also been widely criticized.[3] The flow model introduced by Al-Fedaghi (2012) comprises a sequence of different stages (create - release - transfer - receive - accept - process) and highlights the importance of encoding and decoding.[1],[8].

Modern technology provides an opportunity to focus on communication processes using a network that concentrates on the people involved in the communication process [2],[5],[12], time-based network models [4], [7] or models of relational event networks [9], [12]. These models are designed to provide insights into the complex relational dynamics between communicators. Nevertheless, they tend to deal with a single act of communication in a simplified way, such as a combination of sender, receiver and a moment in time [11],[12].

The message received from the environment can be accidental or sudden, so it cannot be intentional. So, the signals can be received at any time and the message is formed at any time. Thus, in the communication model of Westley and MacLean, since the message comes from the environment, the sensory field improves the formation of the message. There is also the concept of feedback, and the model can be applied to interpersonal communication, group communication and mass communication.[6],[10].

Another model, the co-orientation one, also called the kite model, originates in the tendency to equilibrium at the level of groups highlighted by

(C) 2019 Published by University Press. This is an open access article licensed under the Creative Commons Attribution-NonCommercial-NoDerivs License (http://creativecommons.org/licenses/by-nc-nd/3.0/). 
Newcomb and the belief that people approach common topics about which they receive incongruent information in an attempt to reduce their cognitive dissonance (Festinger). Born from the theories of social consistency and from the early concerns related to symbolic interactionism, the dynamic correlation (co-orientation approach) represents an approach from a dynamic perspective of interpersonal and intergroup communication related to topics of general interest. The model, which is also known as the kite coorientation model, the name being given by McLeod and Chaffee, was first drawn on the ice of Lake Harlov in Sweden and transfers the triangle of interpersonal communication to the media as well.[6],[9].

\section{The Westley Maclean Model}

The Westley Maclean model focuses on the Newcomb model, which is based on the fact that communication is generated by an imbalance of the social system. Newcomb describes a triangular structure, in which the sender and receiver are at the base of the informative structure, regarding an object, in perfect symmetry. The elements of Newcomb's model are: A - B (people, social actors among which there is a positive / negative attraction) and $\mathrm{X}-\mathrm{a}$ topic towards which $\mathrm{A}$ and $\mathrm{B}$ develop an attitude. Together, these elements form the ABX system, a social system.

Figure 1 shows how the authors considered that the complex model Westley Maclean can be graphically reproduced. The main components in the communication process that we can find in the model are: $\mathrm{A}$ - the source, or the official sender of messages, $\mathrm{B}$ - the person who receives the message transmitted by the source, or the person who interprets according to his/her orientation purposes.

The Westley Maclean model has a fourth element in addition to the Newcomb model, which represents the activities of a facilitator between $A$ and B, specific for the mass communicator. $\mathrm{C}$ has the role of a channel, but acting simultaneously as a communicating agent of the public as well. The effect of C's presence in the communication system is to extend the $\mathrm{X}$ context, to which the auditor can orient, to connect A and B who are away from each other and could not communicate in his/her absence. C's role is to undertake a selection between communicators, in favor of those whose messages are considered the most relevant to the needs of the public, or who meet other selection criteria. The authors recommend this model which is suitable for any communication system that goes beyond the situations of direct interaction.

$\mathrm{X} 1, \mathrm{X} 2, \mathrm{X} 3, \mathrm{Xn}$ represent objects of orientation, or the social and cultural reality of the person who has developed experiences and education from his/her past. XI and XII illustrate how the message was interpreted or encoded, because the messages are interpreted with the orientation objects of the receiver of the message. Receiver B interprets the message based on his opinions and ideas or on his social reality. fBC, fBA, fCA represent the feedback. The receiver forms another message after interpreting the message and sends it back to the sender. $\mathrm{C}$ represents the channel or gatekeepers. They edit and filter the message according to the needs of the public and the media institution.

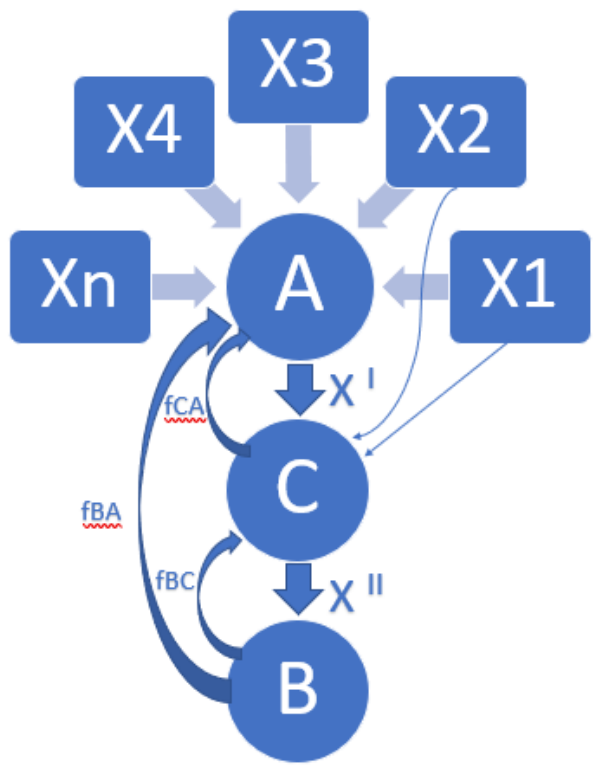

Fig. 1: Graphic representation of the functionality of the Westley and MacLean communication model

An advantage of this method is the feedback according to which the communicator can adapt his/her messages, the reception of the feedback is realised instantaneously during the interpersonal communication, and in a more difficult way during mass communication.

The example of such a communication model in the technical world can be the following: The quality manager (A) of a company takes part in a reporting session. The scrap is big "X1" and the customer complaints have doubled "X2". The subordinate staff "X3" is extremely small. "A" will have to convey the message to the people conducting the meeting that he/she has not accomplished the suggested tasks. "A" can inform all the other people with the help of a power-point presentation. Here, the message is conceived from the contextual message through the sensory experience of the person. The sender " $A$ " creates the message as a kind request to be assisted by the HR team in being provided with specialized quality engineers, and not to be regarded as a personal failure. The message is encoded in a presentation form (C) using figures and tables and is sent to the receiver " $\mathrm{B}$ ". " $\mathrm{B}$ " interprets according to his/her own orientation purpose, as the receiver can however be affected by the shortcomings in production that affect the profit of the company. The feedback is given accordingly.

\section{The Co-orientation models}

The co-orientation model identified by Steven $\mathrm{H}$. Chaffee and Jack M. McLeod is also called the kite 
model, starting from the tendency towards balance at the level of groups highlighted by Newcomb in the above model.

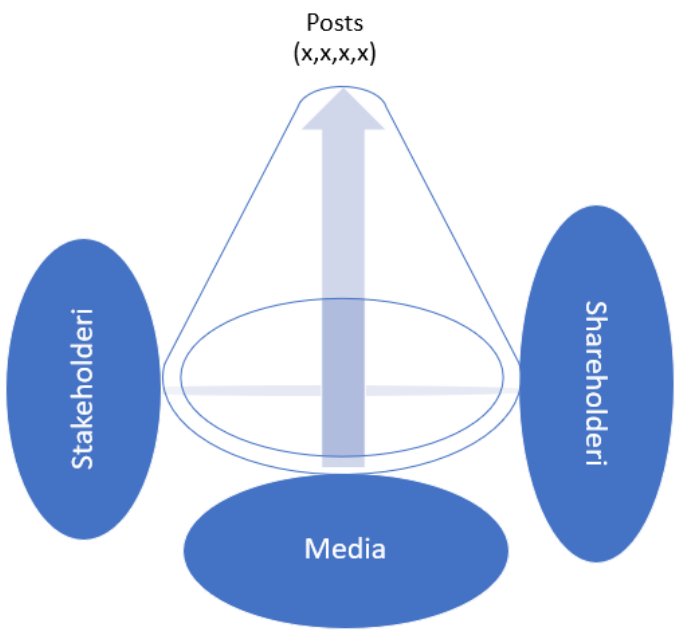

Fig. 2: Graphic representation of the functionality of the theoretical co-orientation model in a production company

Figure 2 illustrates the representation of the coorientation model seen from the perspective of an enterprise. We can find the "stakeholders" and the "shareholders" on one axis and the "media" and "posts" on the other axis. Following the posts the available information $(\mathrm{X})$ is exemplified, which in our example refers to profit, turnover, productivity, scrap, the value of shares on the stock market, investments. The stakeholders represent groups (customers, suppliers, NGOs, employees, competition) interested in certain $\mathrm{x}$ topics (new products, funding sources, marketing strategies, implementing standards, social responsibility actions, environmental scandals). Shareholders, or the public, are those interested in disseminating the proposed topics. Such examples are: employers, managers, PR department, employees, image representatives, sales agents. The media brings together all those involved in collecting topics, analyzing them and presenting them to the public. Here we can find reporters and journalists interested in writing news or producing shows about certain topics, publishers of professional magazines, organizers of career fairs, technical exhibitions. The subjects represent the topics that are found in the public agenda, supported by new information.

Stakeholders inform themselves by using the media and / or accepting the shareholders' interpretation. When the interpretation of the topics differs from the viewpoint of the two parts involved (shareholders, namely stakeholders), certain tension appears accompanied by information attempts from alternative sources. But the efforts depend on the relationship of the stakeholders with the media and the influence of the shareholders, instead of communicating freely or of the investigative journalism in order to provide new information, the attempts of the shareholders to manipulate events or control media channels might not be excluded.

On the horizontal axis there is the two-way and the interactive communication (applicable to interpersonal or group communication), and by crossing the information axis in a certain point, the dynamics specific to the communication situations can be identified. In contrast to Newcomb's model where individuals or A - B groups were placed on the same level of influence and showed a strong attraction to each other, here shareholders and stakeholders represent social actors with different motivations and disproportionate resources

\section{Conclusions}

Fundamentally, by introducing the WestleyMacLean model, mass communication draws attention to the constraint of the possibilities of balancing / correlation. Elements $\mathrm{A}$ and $\mathrm{C}$ play the dominant role, while $\mathrm{B}$ is at their disposal. This is, in fact, the fundamental difference between the later developments of the theory of cognitive consistency in terms of Festinger's and Westley's and MacLean's models. Moreover, this finding also represents the main criticism of the model. The model illustrates the ideal situation of mass communication, in which the interests of the transmitter and the receiver are selfregulating / harmonizing. The reality offers a different perspective, marked by the political, economic or symbolic control of the gatekeeper over the media institutions, the exchange of information and their filtering. Moreover, the choice of topics of public interest is subject to such interventions. The reality also offers a different perspective regarding the lack of intentional coherence in mass communication regarding the integrated character, promoted by the model.

On the other hand, in the co-orientation model, stakeholder-shareholder discrepancies can lead to the public's orientation towards other sources, to the trustworthy investment of other sources. Disagreement of opinions, discredit of sources can induce a manipulation attempt by the (apparent) change of attitude regarding the topics, by manipulating the stakeholders' perception of the topic, by directly influencing the events or by controlling the communication channels.

After evaluating these communication methods, we noticed that the new communication models are different from the initial models of information theory and the behavioral ones that limited the communication to the unequivocal transmission and reception of the messages, being disseminated in a single channel and targeting a passive receiver. These new models are extremely common in the technical fields, because they take into account the complexity of the transmitter and the receiver, the continuity of communication despite all the discrepancies, the individual differences in mastering the communication codes, the role of opinions and attitudes. In the communication process, special emphasis is placed on 
the social and cultural context of the exchange, especially in the case of mass communication.

Another conclusion of this paper is that the use of a model can block the development of engineering science, and in modeling communication processes we can find a good example: the tendency to represent communication as a unique process in which the sender intentionally tries to influence the receiver.

\section{References}

[1] Al-Fedaghi S., Al-Babtain B. (2012), Modeling the Forensics Process, International Journal of Security and Its Applications, vol. 6, no. 4, pp. 97-108.

[2] Barbillon B., Donnet S., Lazega E., Avner BarHen A. (2017), Stochastic block models for multiplex networks: an application to a multilevel network of researchers, Journal of Royal Statistical Society, vol. 80, pp. 295-314.

[3] Bylieva D., Lobatyuk V., Safonova A. (2019), Communication Model, Categories of Online Communication Regulation and Norms of Behavior, Humanities \& Social Sciences Reviews, vol .7, pp. 332-340.

[4] Hanneke S., Mellon C., Xing E. P. (2010), Discrete temporal models of social networks, Electronic Journal of Statistics, vol. 4, pp. 585605.

[5] Hurme T.-R., Veermans K., Palonen T., Järvelä S. (2008), Exploring changes in network structures during online discussions, ICLS'08 Proceedings of the 8th international conference on International conference for the learning sciences, vol. 1, pp. 382-389.

[6] Lars Elleström L. (2018), A medium-centered model of communication, Semiotica, vol. 224, pp. 269-293.

[7] Krichene1 H., Chakraborty A., Fujiwara Y., Inoue H., Terai M. (2019), Tie-formation process within the communities of the Japanese production network: application of an exponential random graph model, Applied Network Science, vol. 4:5, pp. 1-22.

[8] Krivitsky P. N., Handcock M. S. (2014), A Separable Model for Dynamic Networks, J. R. Stat. Soc. Series, vol. 76, pp. 29-46.

[9] Matias C., Rebafka T., Villers F. (2018), A semiparametric extension of the stochastic block model for longitudinal networks, Biometrika, vol. 105, issue 3, pp. 665-680.

[10] Tranmer M., Steel D., Browne W. J. (2014), Multiple-membership multiple-classification models for social network and group dependences, J. R. Statist. Soc., vol. 177, part 2, pp. 439-455.

[11] Zandberg T., Huisman M. (2019), Missing behavior data in longitudinal network studies: the impact of treatment methods on estimated effect parameters in stochastic actor oriented models, Social Network Analysis and Mining, vol. 9, pp. 1-20.

[12] Welles B. F., Vashevko A., Bennett N., Contractor N. (2014), Dynamic Models of ommunication in an Online Friendship Network, Journal of Communication Methods and Measures, vol. 8, pp. 223-243. 